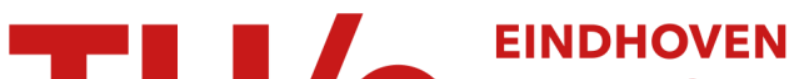

\section{Effects of nano-silica (NS) additions on durability of SCC mixtures}

Citation for published version (APA):

Quercia Bianchi, G., Spiesz, P. R., \& Brouwers, H. J. H. (2015). Effects of nano-silica (NS) additions on durability of SCC mixtures. In C. Andrade, JJW. Gulikers, \& R. Polder (Eds.), Durability of Reinforced Concrete from Composition to Protection (pp. 125-143). Springer. https://doi.org/10.1007/978-3-319-09921-7

DOI:

10.1007/978-3-319-09921-7

Document status and date:

Published: 01/01/2015

\section{Document Version:}

Publisher's PDF, also known as Version of Record (includes final page, issue and volume numbers)

\section{Please check the document version of this publication:}

- A submitted manuscript is the version of the article upon submission and before peer-review. There can be important differences between the submitted version and the official published version of record. People interested in the research are advised to contact the author for the final version of the publication, or visit the $\mathrm{DOI}$ to the publisher's website.

- The final author version and the galley proof are versions of the publication after peer review.

- The final published version features the final layout of the paper including the volume, issue and page numbers.

Link to publication

\section{General rights}

Copyright and moral rights for the publications made accessible in the public portal are retained by the authors and/or other copyright owners and it is a condition of accessing publications that users recognise and abide by the legal requirements associated with these rights.

- Users may download and print one copy of any publication from the public portal for the purpose of private study or research.

- You may not further distribute the material or use it for any profit-making activity or commercial gain

- You may freely distribute the URL identifying the publication in the public portal.

If the publication is distributed under the terms of Article $25 \mathrm{fa}$ of the Dutch Copyright Act, indicated by the "Taverne" license above, please follow below link for the End User Agreement:

www.tue.nl/taverne

Take down policy

If you believe that this document breaches copyright please contact us at:

openaccess@tue.nl

providing details and we will investigate your claim. 


\title{
Effects of Nano-silica (NS) Additions on Durability of SCC Mixtures
}

\author{
G. Quercia, P. Spiesz, and H.J.H. Brouwers
}

\begin{abstract}
In this study, three different types of nano-silica were applied in self-compacting concrete (SCC), one produced by the controlled dissolution of the olivine mineral and two having similar particle size distributions (PSD), but produced through two different processes: fumed powder nano-silica and precipitated silica in colloidal suspension. The influence of the nano-silica on SCC was investigated with respect to the properties of the concrete in fresh (workability) and hardened state (durability properties). Additionally, the densification of the microstructure of the hardened concrete was analyzed by SEM and EDS techniques. The obtained results demonstrate that an efficient use of nano-silica in SCC can improve its durability properties. Considering the reactivity of the different nano-silica studied, the colloidal type showed a higher reactivity at early age, which influenced the final SCC properties.
\end{abstract}

Keywords Self-compacting concrete $\bullet$ Nano-silica $\bullet$ Olivine $\bullet$ Chloride $\bullet$ Freezethaw

\section{Introduction}

Currently, the micro-level does not provide enough insights into building materials. Therefore, all around the world, increasing amounts of funding are being directed to research projects dealing with material properties on nano-level, which is claimed to have tremendous potential for the future (Scrivener and Kirkpatrick 2008).

\footnotetext{
G. Quercia (四)

Trican Well Service Ltd, Calgary R\&D Centre, Canada

e-mail: gquercia@trican.ca

P. Spiesz

Department of the Built Environment, Eindhoven University of Technology,

Eindhoven, The Netherlands
}

ENCI HeidelbergCement Benelux, The Netherlands

e-mail: p.spiesz@tue.nl; przemek.spiesz@heidelbergcement.com

H.J.H. Brouwers

Faculty of the Built Environment, Eindhoven University of Technology,

Eindhoven, Netherlands 
The fundamental processes that govern the properties of concrete are affected by the performance of the material on nano-scale. The main hydration product of cement-based materials, the CSH-gel, is a nano-structured material (Scrivener and Kirkpatrick 2008; Sanchez and Sobolev 2010). The mechanical properties and the durability of concrete mainly depend on the refinement of the microstructure of the hardened cement paste and the improvement of the paste-aggregate interface zone - ITZ - (Nili et al. 2010).

One of the most referred to and used cementitious nano-materials is amorphous silica with a particle size in the nano-range, even though its application and effects on concrete have not been fully understood yet. It has been reported that the nano-silica addition increases the compressive strength and reduces the overall permeability of hardened concrete due to its pozzolanic properties, which result in finer hydrated phases (CSH-gel) and densified (nano-filler and anti-Ca(OH)$)_{2}$-leaching effect) microstructure (Rols et al. 1999; Ji 2005; Sobolev and Ferrara 2005; Lin et al. 2008; Gaitero et al. 2008; Belkowitz and Armentrout 2010; Quercia and Brouwers 2010). These effects may enhance the durability of concrete elements and structures.

There are different commercial types of nano-silica additives available on the market which are produced in different ways such as precipitation from olivine mineral dissolution, pyrolysis, sol-gel and others (Quercia and Brouwers 2010). The main characteristics of nano-silica, such as the particle size distribution, specific density, specific surface area, pore structure, and reactivity (surface silanol groups), depend on the production method. Despite the existence of several studies that describe the main properties and characteristics of concrete containing nano-silica particles, most of them focus on the application of nano-silica as an anti-bleeding (Okamura and Ozawa 1995; Rols et al. 1999; Sari et al. 1999; Audenaert et al. 2007; Byung et al. 2007; Maghsoudi and Arabpour-Dahooei 2007; Khanzadi et al. 2010) and compressive strength enhancing additive (Li 2004; Gaitero et al. 2008; RaiessGhasemi et al. 2010; Wei and Zhang 2011). Furthermore, the durability and sustainability of concrete structures is becoming of vital importance for the construction industry. In this context, SCC is a type of concrete that has generated tremendous interest since its initial development in Japan by (Okamura and Ozawa 1995).

SCC was developed to obtain durable concrete structures due to an increased homogeneity. For this purpose, a concrete with low yield stress, moderate viscosity and high resistance to segregation, which also can be cast on-site or into precast molds without compaction, was developed. The special flow behavior of SCC is obtained by the use of superplasticizers, high amounts of fine particles, and, in some cases, viscosity modifying agents (added to reduce segregation and bleeding). Due to the presence of high amounts of fines, the pore structure of SCC differs from the pore structure of traditional concrete. According to (Audenaert et al. 2007), the application of SCC might be somewhat risky due to the lack of knowledge concerning the actual durability of this material.

So far, only a few reports on the effects of nano-silica on the durability of SCC are available (Maghsoudi and Arabpour-Dahooei 2007; Raiess-Ghasemi et al. 2010; Wei and Zhang 2011). In addition, the difference in the reactivity of nano-silica due to its production route has not been reported yet. 
In this study, three different types of nano-silica were applied in SCC, one produced by the controlled dissolution of the olivine mineral and two having similar particle size distributions (PSD), but produced through two different processes: fumed powder nano-silica and precipitated silica in colloidal suspension. The influence of the nano-silica on SCC was investigated with respect to the properties of the concrete in fresh (workability) and hardened state (durability properties). In addition, the densification of the microstructure of the hardened concrete was analyzed by SEM and EDS techniques.

\section{Materials and Methods}

\subsection{Materials and SCC Mix Design}

The Portland cement used was CEM I 42.5 N, as classified by (EN 197-1 2000). The coarse aggregates used were composed of broken granite in the fractions 2-8 $\mathrm{mm}$ and 8-16 $\mathrm{mm}$. Two different sands were used: dredged river sand $(0-4 \mathrm{~mm})$ and microsand $(0-1 \mathrm{~mm})$. The microsand is mainly composed of natural sandstone waste that is generated during the crushing process of coarser fractions. A ground limestone powder was applied as filler. Three different nano-silica additives were selected to produce three different SCC batches: one colloidal nano-silica suspension ( $\mathrm{CnS}-2)$, one fumed powder nano-silica $(\mathrm{PnS}-3)$ and one water based suspension with $10 \mathrm{wt}$ \% of nano-silica precipitated from the olivine dissolution (DOnS-8). The two first nano-silica additives ( $\mathrm{CnS}-2$ and $\mathrm{PnS}-3)$ have similar PSD and specific surface area measured by the BET method (Brunauer et al. 1938), following the standard (DIN-ISO 9277 2005). Furthermore, a superplasticizer (SP1) based on polycarboxylate ethers was added to adjust the workability of the mix. A summary of the general characteristics of all materials used is presented in Table 1. Their PSDs are depicted in Fig. 1.

For the composition of SCC mixes, the mix design concept described in (Hunger 2010) was used. This design concept makes use of an optimization algorithm described in (Hüsken and Brouwers 2008) to compute the mix proportions of all solid ingredients of the concrete mix, following the theory of continuously graded granular mixtures. In the optimization process, a distribution modulus $(q)$ of 0.25 was used together with the following constrains: cement content of $340 \mathrm{~kg} / \mathrm{m}^{3}, w / c$ ratio of 0.45 , air content in the fresh mix of $1 \%$ by volume and nano-silica content of $3.8 \%$ bwoc. The cement content and the $w / c$ ratio were selected based on (NEN-EN 206-1 2008) for the exposure class XS3 (aggressive exposure to chlorides originating from seawater). In addition, a flow class of the fresh concrete F7 (630-800 mm) was selected as a target, taking into consideration the Dutch recommendation (BRL 18012006 ) for SCC. An example of the target curve and the composed grading curve of the SCC mix is also shown in Fig. 1. 
Table 1 Properties of the used materials

\begin{tabular}{l|l|l|l|l|l|c}
\hline Materials & $\begin{array}{l}\text { Specific } \\
\text { density } \\
\left(\mathrm{g} / \mathrm{cm}^{3}\right)\end{array}$ & $\begin{array}{l}\mathrm{BET} \\
\left(\mathrm{m}^{2} / \mathrm{g}\right)\end{array}$ & $\mathrm{pH}$ & $\begin{array}{l}\text { Solid content } \\
(\% \mathrm{w} / \mathrm{w})\end{array}$ & $\begin{array}{l}\text { Loss on } \\
\text { ignition } \\
(\%)\end{array}$ & $\begin{array}{l}\text { Computed SSA } \\
\left(\mathrm{m}^{2} / \mathrm{m}^{3}\right)\end{array}$ \\
\hline CEM I 42.5 N & 3.14 & 1 & - & - & 2.8 & $1,699,093$ \\
\hline CnS-2 & 1.40 & 50 & 9.5 & 50 & - & $46,110,081$ \\
\hline PnS-3 & 2.15 & 56 & $5.0^{\mathrm{a}}$ & - & 0.5 & $48,175,461$ \\
\hline OnS-15 & 2.10 & 400 & $5.8^{\mathrm{a}}$ & - & - & $179,142,530$ \\
\hline $\begin{array}{l}\text { Limestone } \\
\text { powder }\end{array}$ & 2.71 & - & - & - & - & $1,234,362$ \\
\hline $\begin{array}{l}\text { Microsand } \\
\text { (sandstone) }\end{array}$ & 2.64 & - & - & - & - & 193,514 \\
\hline Sand 0-4 & 2.64 & - & - & - & - & 14,251 \\
\hline Granite 2-8 & 2.65 & - & & - & - & 1,740 \\
\hline Granite 8-16 & 2.65 & - & - & - & - & 515 \\
\hline Superplasticizer & 1.10 & - & 7.0 & 35 & - & - \\
\hline
\end{tabular}

${ }^{\mathrm{a}} 4 \% \mathrm{w} / \mathrm{w}$ in water

Fig. 1 PSD of the used materials, target function and composition of reference mix (dashed line) for $\mathrm{D}_{\min }=60 \mathrm{~nm}$

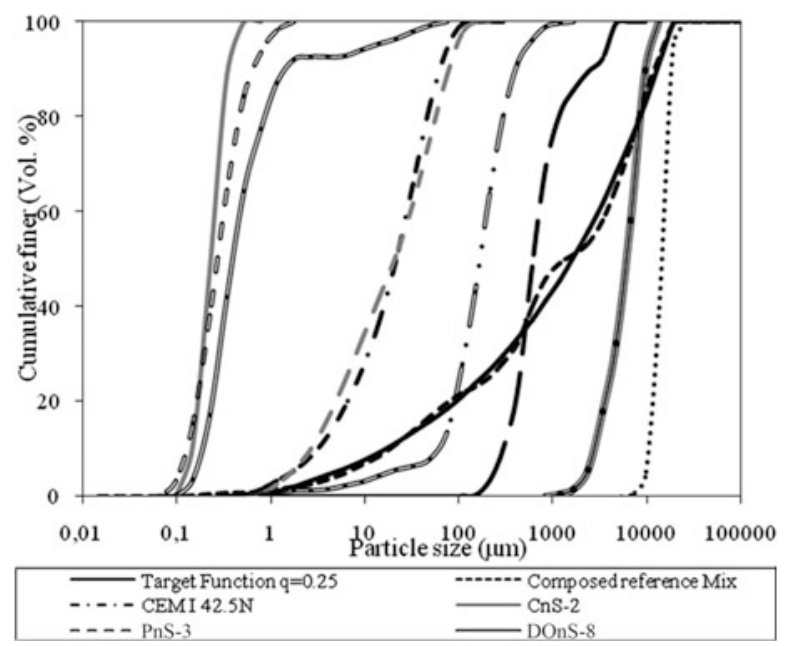

\subsection{Test Methods}

\subsubsection{Fresh Concrete Properties}

Using the provided materials, four SCC mixes (two batches of $65 \mathrm{dm}^{3}$ for each mix) were prepared according to the mix proportions listed in Table 2. These SCCs were mixed for $5 \mathrm{~min}$ in total in a compulsory mixer, and subsequently tested for their fresh concrete properties, according to the recommended procedure (EFNARC 2005). The following fresh-concrete properties of the SCC were determined: V-funnel time, slump flow, density, packing density and air content. 
Table 2 SCC concrete mix designed using the optimization tool developed by (Hüsken and Brouwers 2008)

\begin{tabular}{l|l|l|l|l}
\hline Materials & Reference & CnS-2 & PnS-3 & DOnS-8 \\
\hline & \multicolumn{2}{l}{ Concentration in $\mathrm{kg} / \mathrm{m}^{3}$} & \multicolumn{2}{l}{} \\
\hline CEM I 42.5 N & 340.0 & 340.0 & 340.1 & 340.1 \\
\hline Nano-silica & 0.0 & 12.8 & 12.8 & 12.8 \\
\hline Limestone powder & 179.4 & 151.8 & 151.9 & 151.8 \\
\hline Microsand $($ sandstone) $0-1 \mathrm{~mm}$ & 125.0 & 141.3 & 141.4 & 141.3 \\
\hline Dredged sand 0-4 mm & 624.3 & 617.9 & 618.0 & 617.8 \\
\hline Granite $2-8 \mathrm{~mm}$ & 733.8 & 735.6 & 735.7 & 735.5 \\
\hline Granite $8-16 \mathrm{~mm}$ & 274.7 & 274.2 & 274.3 & 274.2 \\
\hline Water & 153.0 & 153.0 & 153.0 & 168.4 \\
\hline Superplasticizer $(\mathrm{SP} 1 \mathrm{PCE}-\mathrm{type})$ & 3.4 & 6.5 & 6.5 & 11.1 \\
\hline Air $($ Vol. $\%)$ & 1.0 & 1.0 & 1.0 & 1.0 \\
\hline Density $\left(\mathrm{g} / \mathrm{cm}^{3}\right)$ & 2.427 & 2.427 & 2.430 & 2.426 \\
\hline$w / c$ & 0.45 & 0.45 & 0.45 & 0.50 \\
\hline$w / p$ & 0.267 & 0.270 & 0.270 & 0.297 \\
\hline Powder content $\left[1 / \mathrm{m}^{3}\right]$ & 194.2 & 192.7 & 192.6 & 192.8 \\
\hline Composed surface $\left(\mathrm{m}^{2} / \mathrm{m}^{3}\right)$ & 277,972 & 547,905 & 554,428 & 940,678 \\
\hline SP1 content $\left(\mathrm{g} / \mathrm{m}^{2}\right)$ & 0.0122 & 0.0119 & 0.0117 & 0.0118 \\
\hline SP1 content $\left(\% \mathrm{bwoc}^{2}\right)$ & 1.0 & 1.9 & 1.9 & 3.3 \\
\hline
\end{tabular}

bwoc based on the weight of cement

\subsubsection{Hardened Concrete: Durability Tests}

\section{Permeable (Water Accessible) Porosity}

The permeable porosity affects the transport properties of fluids in concrete and therefore also its durability. It is related to many deterioration processes driven by the transport properties of concrete (Safiuddin and Hearn 2005). In this context, three cores (diameter of $100 \mathrm{~mm}$, height of $150 \mathrm{~mm}$ ) were drilled with a diamond coring bit from three cubes for each mix. Afterwards, using a diamond saw at medium speed lubricated with water, six concrete discs (height of approximately $15 \mathrm{~mm}$ ) for each SCC mix were cut from the inner layers of the drilled cores. No polishing of the surface was performed. In total 18 discs were used to determine the permeable porosity, following the procedure described by (ASTM 1202 2005). The vacuum-saturation technique was applied to fill the accessible pores with water, as this technique is concluded to be the most efficient by (Safiuddin and Hearn 2005).

\section{Penetration of Water Under Pressure}

The depth of penetration of water under pressure was tested according to (BS-EN $12390-8,2009$ ) at the age of 28 days. The samples (three cubes for the reference and 
two for each mix with nano-silica) were exposed to water under pressure ( 5 bar) for $72 \mathrm{~h}$ and subsequently split in order to determine the maximum depth of the water penetration.

Pore Size Distribution and Porosity of the Paste

The pore size distribution was measured using the mercury intrusion porosimetry (MIP) technique (Autopore IV, Micromeretics). The maximum applied pressure of mercury was $228 \mathrm{MPa}$, the mercury contact angle was $130^{\circ}$ and the equilibrium time was $20 \mathrm{~s}$. The pore size range of $0.0063-900 \mu \mathrm{m}$ was investigated. Pieces of hardened mortar (approximately $2 \mathrm{~g}$ in total) were carefully selected to avoid the presence of coarse sand and gravel. The mortars, extracted from cured SCC samples at 28 days, were first dried in an oven $\left(80^{\circ} \mathrm{C}\right)$ until a constant mass was reached, and then tested by the MIP technique. Only samples from the reference SCC and the SCCs with CnS-2 and PnS-3, respectively, were considered for this study.

\section{Rapid Chloride Migration Test (RCM)}

Two specimens for the RCM test were retrieved from each extracted core giving in total six test specimens (discs, diameter of $100 \mathrm{~mm}$ and height of $50 \mathrm{~mm}$ ) for each mix. Three of these specimens were tested at the age of 28 days and the remaining three at 91 days. One day prior to the RCM test, the specimens were pre-conditioned (vacuum-saturation with limewater). The RCM test was performed according to (NT Build 492 1999), using the test set-up described in (Spiesz et al. 2012). The duration of the RCM test for all samples was $24 \mathrm{~h}$. After the test, the penetration depth of chlorides was measured on split samples by applying a colourimetric indicator for chlorides $\left(0.1 \mathrm{M} \mathrm{AgNO}_{3}\right.$ solution) and the values of the chloride migration coefficients $\left(\mathrm{D}_{\mathrm{RCM}}\right)$ were calculated according to (NT Build 492 1999).

\section{Freeze-Thaw Resistance (Surface Scaling Test)}

As a further durability assessment, the freeze-thaw test was performed on SCC samples, even though the air content in the fresh mix was less than the recommended value of $4 \%$ by volume (NEN-EN 206-1 2008). The freeze-thaw resistance, expressed by the surface scaling factor $(\mathrm{Sn})$, was determined following the procedure described in (NEN-EN 12390-9 2006). Nevertheless, the test samples differed from the specifications in the standard. For practical reasons, cylinders were used instead of slabs (Fig. 2a). The $150 \mathrm{~mm}$ cubes were cured in water after demolding until the age of 14 days, when the cores (100 $\mathrm{mm}$ in diameter) were extracted and sliced (two cylinders of $50 \mathrm{~mm}$ in height were obtained from 
a

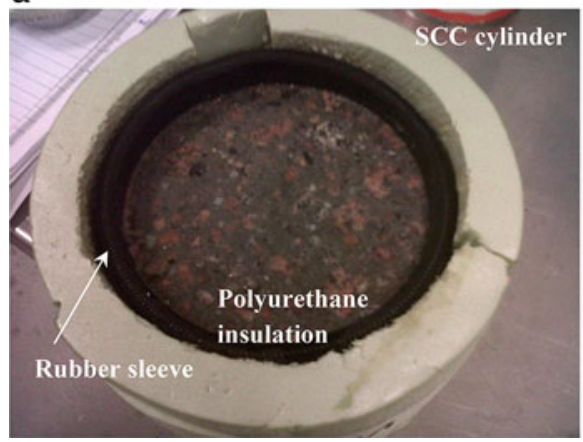

b

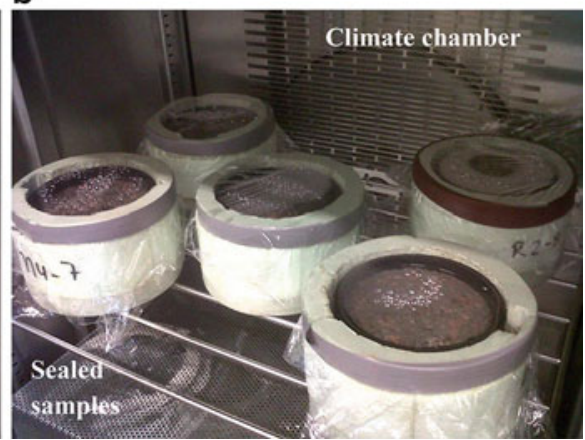

Fig. 2 Used freeze-thaw experimental setup, (a) freeze-thaw samples preparation, (b) samples inside the climate chamber after 1 freeze-thaw cycle

each core). Afterwards, the obtained cylinders were cured under water and then sealed after 25 days with tight rubber sleeves. The sealed samples were placed in polyurethane insulations of $10 \mathrm{~mm}$ thickness (see Fig. 2a) and surface-saturated with demineralized water for 3 days. Due to a limited volume of the used climate chamber (Fig. 2b), only three specimens were tested for each mix, resulting in a total exposed surface area of $0.024 \mathrm{~m}^{2}$, the area recommended in (NEN-EN 12390-9 2006) is $0.08 \mathrm{~m}^{2}$ ). After the saturation, the demineralized water was replaced by a $3 \mathrm{~mm}$ layer of $3 \%$ by weight $\mathrm{NaCl}$ solution, poured on the top surfaces of the samples and then the freeze-thaw cycles were started. The applied temperature profile was following the recommendations given in (NEN-EN 12390-9 2006). The level of solution on the surface of concrete was adjusted regularly. In total, 56 freeze-thaw cycles were performed, during which the surface scaling was measured after 7, 14, 28, 42 and 56 cycles.

\subsubsection{Microstructural Characterization and Analysis}

The microstructural morphology of the prepared concrete was analyzed using a high resolution scanning electron microscope (FEI Quanta 600 FEG-SEM) with a Schottky field emitter gun (at voltage of $10 \mathrm{keV}$ and 0.6 mbar of low-vacuum pressure). Furthermore, a general chemical analysis was performed using EDAX energy dispersive spectroscopy (EDS) detector. Several fracture surfaces were investigated in natural conditions (without any sample preparation). The fracture surfaces of the SCC samples were analyzed in this study to avoid the effect of sample preparation (cutting, grinding, polishing, etc.), which may alter the microstructure of concrete. In the analyses of the fracture surfaces it is possible to characterize the interfacial transition zone (ITZ), the formation of portlandite hexagonal plates and ettringite needles. 


\section{Results and Discussion}

\subsection{Fresh Concrete Properties}

The fresh concrete properties of the tested mixes are presented in Table 3. All four mixes fulfilled the requirements for the flow class F7 (630-800 $\mathrm{mm}$ of spread diameter), specified in (BRL 1801 2006). Only the mix with CnS-2 resulted in a spread flow close to the lower limit of this target range. Another interesting finding is that the SP content, based on the composed surface area, is nearly constant for all mixes and amounts to an average value of $0.0119 \mathrm{~g} / \mathrm{m}^{2}$. This shows that in the present case the required amount of SP can be calculated if the composed surface area of all solid ingredients is known. Nevertheless, the SP dosage depends also on the mineralogy and the surface charge of the fines used (Spiratos et al. 2003; Plank et al. 2009). Another implication of this result is that the SP requirement is rather related to changes in the specific surface area of the mix than to the concentration (by mass) of the nano-silica addition, as it was previously reported by (Sobolev et al. 2006). These researchers concluded that $0.21 \%$ of additional SP is needed for each $1 \%$ of nano-silica added to a standard concrete composition. The SCC with DOnS-8 also fulfils the requirements for the flow class F7.

Another consequence of the high specific surface area (BET of $400 \mathrm{~m}^{2} / \mathrm{g}$ ) and the agglomerated state of the DOnS-8 was the increased water demand. More water was needed to have workability in the specified range $(w / c$ of 0.50$)$. The increase in the mixing water exceeded the maximum $w / c$ ratio of 0.45 recommended for the exposure class XS3. Further analysis is performed in the following sections.

Considering the V-funnel time, only the three mixes with nano-silica $(\mathrm{CnS}-2$, PnS-3 and DOnS-8, respectively) fulfil the requirements of the viscosity class VF2 (funnel time 9-25 s) as established by (EFNARC 2005). In this particular case, the SCC with DOnS-8 presented the lowest V-funnel time (18.8 s) mainly caused by its higher amount of added water and SP. Although the reference mix does not fulfill this viscosity class, it is in the range for a high powder content SCC mix, as proposed by (Hunger 2010). In addition, no segregation or blocking was observed

Table 3 Properties of the prepared SCC mixes in fresh state

\begin{tabular}{|c|c|c|c|c|}
\hline Value & Reference & $\mathrm{CnS}-2$ & PnS-3 & DOnS-8 \\
\hline Slump flow $(\mathrm{mm})^{\mathrm{a}}$ & $690-720$ & $664-701$ & $685-720$ & $670-720$ \\
\hline V-Funnel time (s) & 35.0 & 20.5 & 24.5 & 18.8 \\
\hline Stability time (s) & 69 & 12 & 7.5 & 9.5 \\
\hline Fresh density $\left(\mathrm{g} / \mathrm{cm}^{3}\right)$ & 2.399 & 2.384 & 2.392 & 2.374 \\
\hline Air content $(\text { Vol. } \%)^{\mathrm{b}}$ & 1.15 & 1.79 & 1.58 & 2.17 \\
\hline Packing density $(\%)^{\mathrm{b}}$ & 83.55 & 82.91 & 83.12 & 80.99 \\
\hline
\end{tabular}

${ }^{a}$ Maximum and minimum flow diameter measured

${ }^{\mathrm{b}}$ Calculated value 
for any mixes. A long V-funnel time was already reported as a typical characteristic of SCC with increased amount of limestone powder (Kordts and Breit 2004; Felekoglu 2007).

As also can be seen in Table 3, the SCC mixes with nano-silica have higher air content compared to the reference mix. In this case, SCC with DOnS-8 has the higher air content of all mixes $(2.17 \%)$, which is caused by the higher viscosity of the paste due to the application of particles with high specific surface area (400 vs. $50 \mathrm{~m}^{2} / \mathrm{g}$ ). The air entrainment was also confirmed by the difference between the designed and the measured concrete density (see Table 3).

\subsection{Hardened Concrete: Durability}

\subsubsection{Permeable Porosity}

The results of the measurements of the permeable porosity of the SCC mixes are presented in Table 4 . These results are surprisingly showing that the SCC reference mix has slightly lower porosity $(12.1 \%)$ compared to the mixes containing the three types of nano-silica (12.5-13.1\%). The porosity and the tortuosity of the pores in the hardened cement paste are normally reduced when pozzolanic materials are added, and this influences many properties such as the compressive and splitting tensile strength (Garboczi 1990). Nevertheless, in (Yogendran and Langan 1987) it is stated that for the addition of micro-silica the total pore volume is not necessarily changed, but larger pores appear to be subdivided into smaller pores. Apparently, the same behavior was found for the SCC in the present case. The air content of the fresh mix influenced, probably, the final porosity. Some researchers (Safiuddin and Hearn 2005) state that the vacuum-saturation technique is also able to take void pores into account. This means that the porosity values shown in Table 4 consider also the differences in the air content of the mixes (the lower the air content the lower the permeable porosity). Also, it is known that a higher amount of mixing water will produce higher capillary pores in the set concretes (Neville 2002), which is the case of the SCC with DOnS-8 additions.

Table 4 Twenty-eight-day permeable porosities and penetration depths of water under pressure of the three designed SCC mixes

\begin{tabular}{l|l|l|l|l}
\hline SCC properties & Reference & CnS-2 & PnS-3 & DOnS-8 \\
\hline Permeable porosity (Vol. \%) & $12.07 \pm 0.17$ & $12.45 \pm 0.26$ & $12.48 \pm 0.23$ & $13.06 \pm 0.38$ \\
\hline Penetration depth of WUP $(\mathrm{mm})$ & $26 \pm 7$ & $3 \pm 2$ & $3 \pm 2$ & $10 \pm 3$ \\
\hline
\end{tabular}

${ }^{\mathrm{a}}$ WUO: water under pressure ( 5 bar) 


\subsubsection{Penetration of Water Under Pressure}

The test results of the penetration of water under pressure are shown in Table 4 . According to (Raiess-Ghasemi et al. 2010), all tested samples are in the low permeability range (penetration depth of less than $30 \mathrm{~mm}$ ). Additionally, the two SCC with CnS-2 and PnS-3 types of nano-silica presented penetration depths less than $5 \mathrm{~mm}$. The SCC with DOnS-8 resulted in a penetration depth of $10 \mathrm{~mm}$. This means that despite the higher $\mathrm{w} / \mathrm{c}$ ratio used and total permeable porosity measured the addition of olivine nano-silica improved or modified the microstructure of the pores, probably changing its tortuosity or shapes. This implies, in general, that the addition of $3.8 \%$ nano-silica results in concrete which is highly resistant to the penetration of water under pressure of $0.5 \mathrm{MPa}$ ( 5 bar). Similar permeability improvements were reported by (Raiess-Ghasemi et al. 2010) for conventional concrete with micro and nano-silica addition. The results also suggest that, despite the similar permeable porosity of all SCC mixes, the nano-silica samples have very low effective water permeability (less interconnected pores and/or finer pore structure).

\subsubsection{Pore Size Distribution and Porosity of the Concrete Matrix}

To support the findings hardened mortar (matrix) of the concrete samples were analyzed using mercury intrusion porosimetry (MIP). The obtained results are shown in Figs. 3 and 4 for the reference, CnS-2 and PnS-3 SCCs, respectively. In addition, the properties of the hardened matrix (mortar) of SCC mixes obtained from MIP measurements are shown in Table 5. In Figs. 3 and 4 one can notice that the addition of $3.8 \%$ of nano-silica slightly increases the volume of pores smaller than $20 \mathrm{~nm}$ (indicated with black arrows in Figs. 3 and 4). Similar trends were obtained for the overall parameters that were extracted from the mercury intrusion test.

It is clearly shown that the addition of nano-silica decreased the median pore diameter (by volume and area) and the average pore diameter, which is reduced from $27.8 \mathrm{~nm}$ (for the reference) to 24.3 and $25.9 \mathrm{~nm}$ for the colloidal nano-silica and powder nano-silica, respectively. Apparently, a reduction of $4 \mathrm{~nm}$ in the average pore diameter was enough to significantly reduce the permeability of the SCC containing nano-silica. This means that the modification of the SCC pore structure due to nano-silica addition is reflected in changes in the medium capillary pores and the gel pores (the minimum pore size detected with MIP was $8 \mathrm{~nm}$ ). Permeability and penetration of harmful substances into concrete are affected mainly by the large and medium capillary pores (Neville 2002). Apparently, nano-silica made the pore structure of paste more homogeneous by increasing medium capillary porosities. In a similar way, the gel pores volume was increased (see Fig. 4). The increased gel porosity can be caused by an increased amount of CSH-gel in the paste, due to an acceleration effect of the nano-silica. The increased gel porosity could result from a higher hydration degree and from the properties of the gel produced by the pozzolanic 


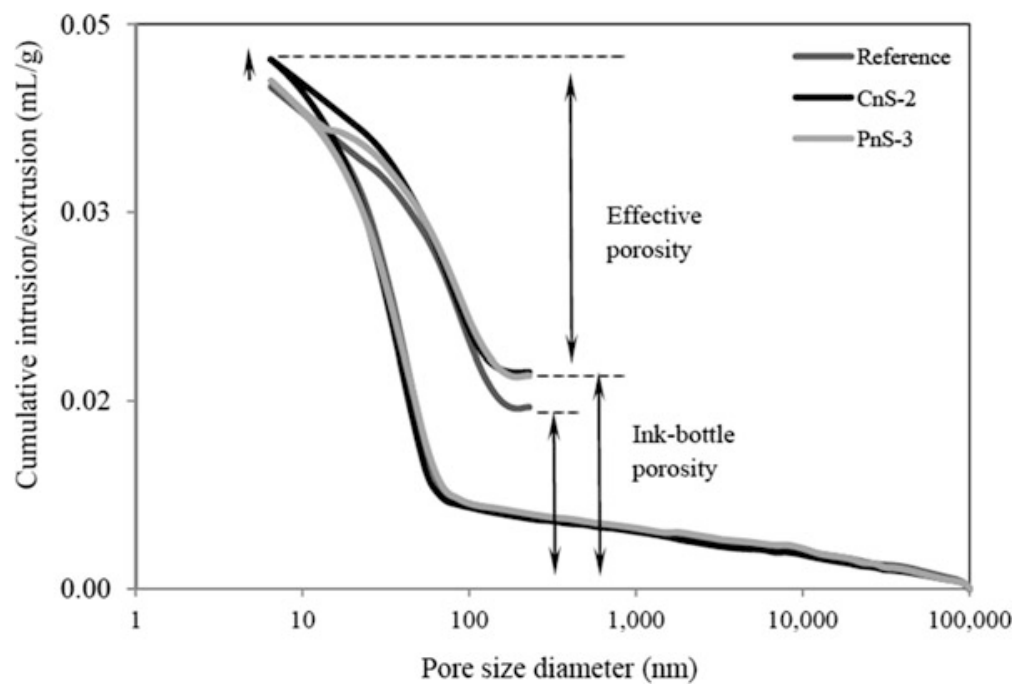

Fig. 3 Cumulative intrusion/extrusion vs. pore size curves of hardened paste extracted from the tested SCC mixes. Black arrows in the figures indicate changes or displacement of the curves due to the addition of nano-silica

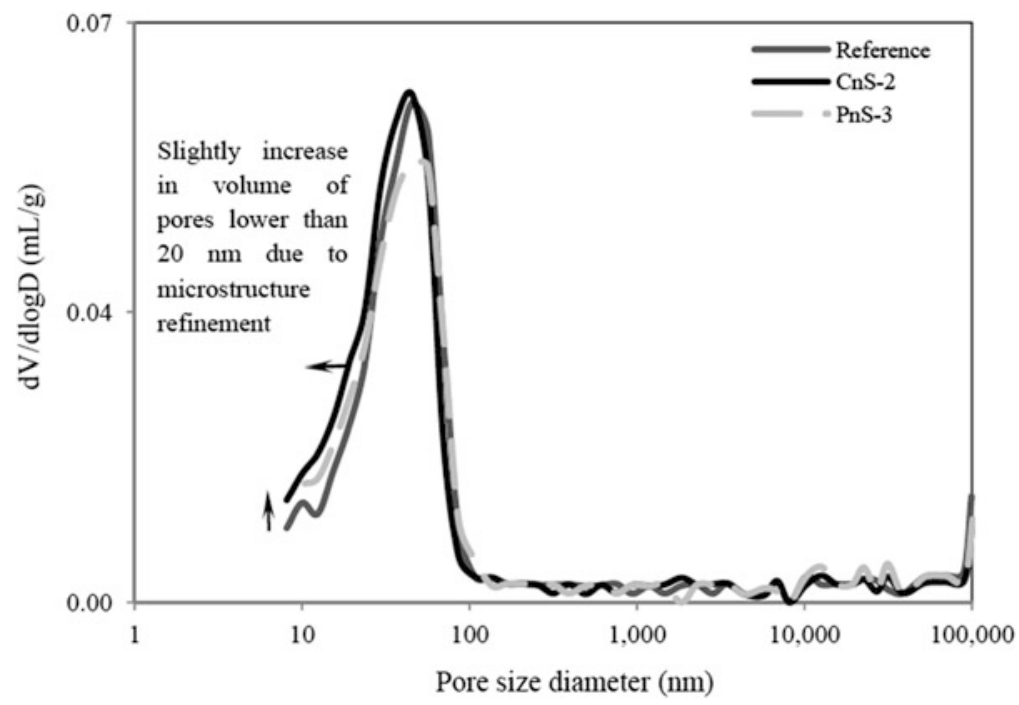

Fig. 4 Log differential intrusion vs. pore size curves of hardened paste extracted from the tested SCC mixes. Black arrows in the figures indicate changes or displacement of the curves due to the addition of nano-silica 
Table 5 Properties of the hardened matrix (mortar) of SCC mixes obtained from MIP measurements

\begin{tabular}{l|l|l|l}
\hline Properties & Reference & CnS-2 & PnS-3 \\
\hline Median pore diameter by volume $(\mathrm{nm})$ & 34.8 & 30.9 & 33.8 \\
\hline Median pore diameter by area $(\mathrm{nm})$ & 20.3 & 17.2 & 17.5 \\
\hline Average pore diameter, $4 \mathrm{~V} / \mathrm{A}^{+}(\mathrm{nm})$ & 27.8 & 24.3 & 25.9 \\
\hline Bulk density at $0.1 \mathrm{MPa}(\mathrm{g} / \mathrm{ml})$ & 2.216 & 2.222 & 2.239 \\
\hline Apparent skeletal density* $(\mathrm{g} / \mathrm{ml})$ & 2.415 & 2.438 & 2.445 \\
\hline Porosity $(\%)$ & 8.79 & 9.31 & 8.99 \\
\hline
\end{tabular}

$(*)$ : Determined excluding the $\mathrm{Hg}$ accessible pores, $(+)$ : ratio between four times median pore diameter by volume and the median pore diameter by area $(4 \mathrm{~V} / \mathrm{A})$

reaction of the nano-silica particles. Pozzolanic CSH-gels, normally, have a lower $\mathrm{Ca} / \mathrm{Si}$ (1-0.8) ratio and different gel porosities (Lothenbach et al. 2011).

Isolated (non-accessible) pores do not contribute to the transport properties of fluids and cannot be detected by MIP. Nevertheless, taking into account the differences between the intrusion and the extrusion cycles of mercury (Fig. 3) and the definition of effective porosity and ink-bottle porosity defined in (Ye 2003), it is possible to observe that the addition of nano-silica increased the amount (volume) of ink-bottle pores. The increment is around $7 \%(+0.0028 \mathrm{~mL} / \mathrm{g})$ for both types of nano-silicas. The transport of species through the ink-bottle pores is more difficult due to their constrictivity. These differences can explain the changes observed in the pores structure of the cement pastes and can partially explain the results of water pressure penetration test, including the WUP results obtained with DOnS-8. Even though, the MIP analysis performed gives some evidence of the changes in the concrete pore structure, the results are close to the test repeatability. For that reason, complementary pore size distribution analyses and other characterization techniques enabling to detect changes in the pore structure are recommended in further research.

\subsubsection{Rapid Chloride Migration Test (RCM)}

The Rapid Chloride Migration test, performed according to (NT Build 492 1999), is a commonly used accelerated technique for determining the chloride transport rate in concrete. The output of the test (the so-called chloride migration coefficient $D_{R C M}$ ) is regularly employed in service-life design models for concrete elements and structures exposed to chlorides. In this context, Fig. 5 presents the average values of the calculated chloride migration coefficients $\left(\mathrm{D}_{\mathrm{RCM}}\right)$ of each SCC mix studied.

Like the conductivity test results, the migration coefficients are much lower for the mixes containing nano-silica. Additionally, the SCC mix with $\mathrm{CnS}-2$ shows again the best performance. On the contrary, the SCC mix with DOnS-8 showed similar performance than the reference mix even thought its higher w/c ratio. The explanation of this behavior is the same as previously discussed a finer 


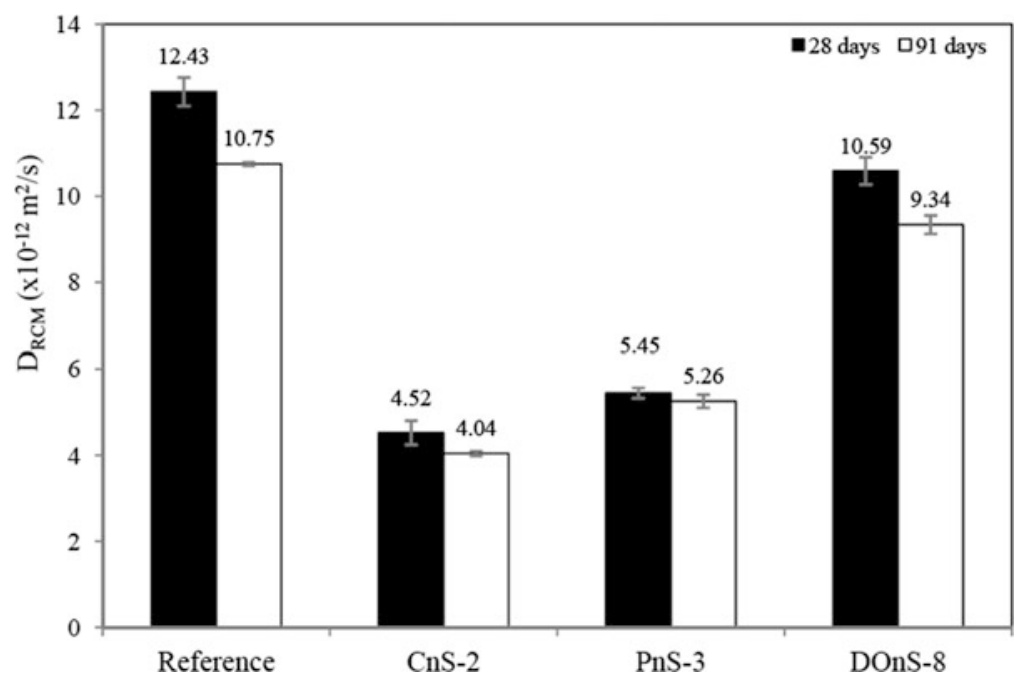

Fig. 5 Twenty-eight and ninety-one days SCC chloride migration coefficient (DRCM)

porosity, greater tortuosity and more precipitated CSH-gel decrease the mobility of the chloride ions into the SCC pore solution. It can also be noticed that the 91 days $\mathrm{D}_{\mathrm{RCM}}$ values are lower compared to the 28 days $\mathrm{D}_{\mathrm{RCM}}$. This can be explained by the progressing hydration of cement and a related densification of the microstructure of concrete.

\subsubsection{Freeze-Thaw Resistance}

The results of the freeze-thaw surface scaling of the four selected SCC mixes are shown in Fig. 6. The failure of the SCC reference mix, taking into account the maximum scaling criteria of $1.5 \mathrm{~kg} / \mathrm{m}^{2}$ at 28 cycles as recommended in (Romero et al. 2011), occurred about the 11th cycle. On the other hand, the SCC mixes with CnS-2 and PnS-3 addition resulted in a surface scaling factor lower than the recommended value for non-air entrained concrete after 28 cycles. These SCC mixes failed the $1.5 \mathrm{~kg} / \mathrm{m}^{2}$ criterion after 52 cycles. In contrast, the SCC with DOnS-8 additions showed a scaling factor lower than the reference ( 21 cycles) but higher than the specified limit for non-air entrained concrete until 28 cycles. Better resistance to the freeze-thaw cycles of the SCC with DOnS-8 additions can be attributed to its denser microstructure and higher air content compared to the reference (see Table 2). The highly stiff $\mathrm{CSH}$-gel and the refined pore structure results in a limited intrusion of water and in an improved resistance to changes of temperature in the concrete surface.

The freeze-thaw resistance depends on the compressive strength, porosity, air void content and other parameters such as the air-voids distribution and pore size (Neville 2002). A better resistance to the freeze-thaw induced damage of the SCC 


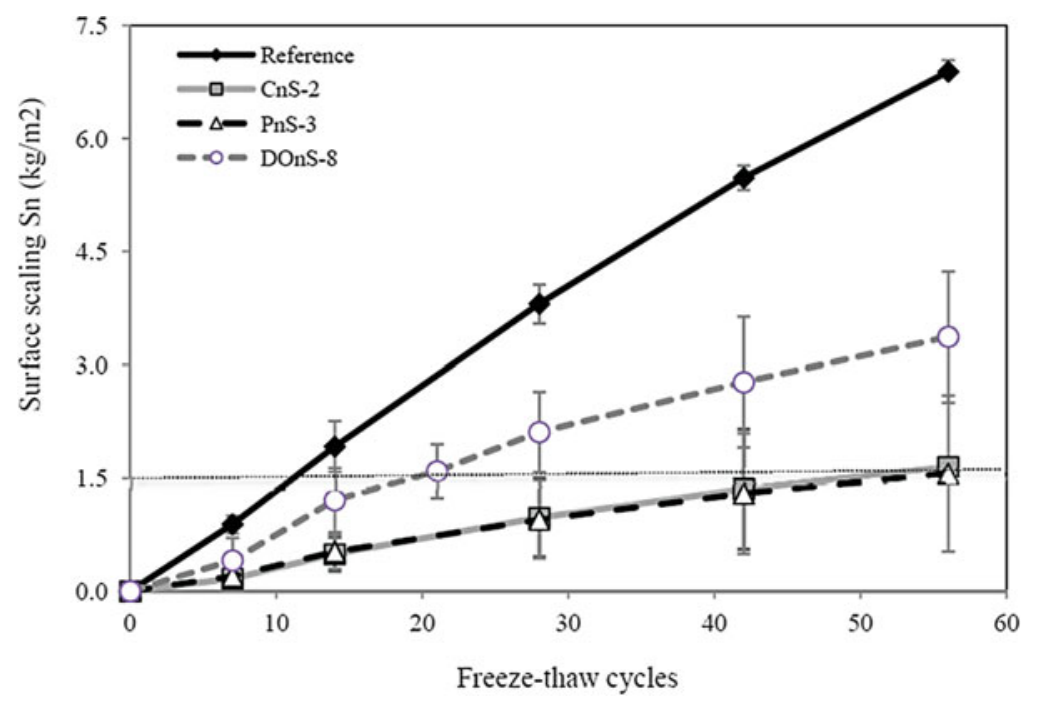

Fig. 6 Cumulative scaling factor ( $\mathrm{Sn}$ ) after 56 freeze-thaw cycles ( $3 \% \mathrm{NaCl}$ solution)

with nano-silica addition can be attributed to different factors, such as the formation of highly stiff CSH-gel with E modules of $26 \mathrm{GPa}$ reported by (Mondal et al. 2010) and the refined pore structure (higher tortuosity and constrictivity of the pores), which results in a limited intrusion of water and in improved resistance to the changes of temperature near the surface of the concrete. Despite the better freezethaw resistance of the SCC with nano-silica compared to the reference mix, its scaling values are larger than the recommended value of $0.5 \mathrm{~kg} / \mathrm{m}^{2}$ after 56 cycles, suggested by (Stark and Wicht 2001) for a concrete classified as having good resistance against freeze-thaw exposure. Nevertheless, with an air entrainment admixture that guarantees a minimum air content of $4 \%$, the freeze-thaw resistance of SCC with nano-silica should result in a mix having a high resistance to freeze-thaw.

\subsection{Microstructural Analysis}

The objective of the microstructural analysis is to support the findings shown in the present research. It is important to notice, that the performed microstructural analyses were qualitative, with the objective to give additional information that can explain the results obtained in the other executed tests.

The SCC with colloidal nano-silica shows a more homogeneous microstructure compared to the reference mix. As an example, Fig. 7a shows the results obtained for CnS-2 SCC. A homogenous microstructure is defined by a more regular morphology and similar size of the hydrates. This microstructure is characterized 
a

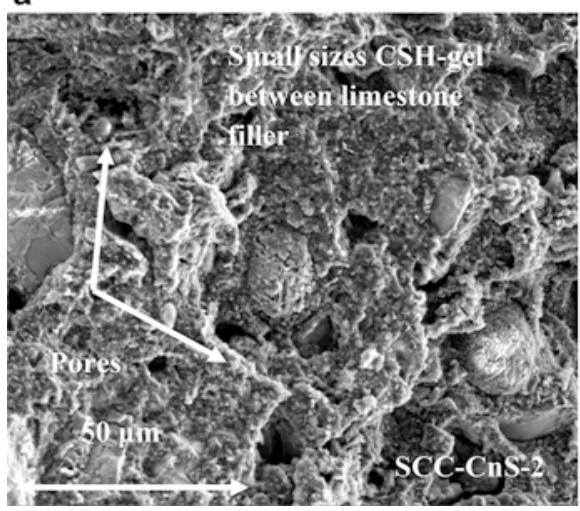

b

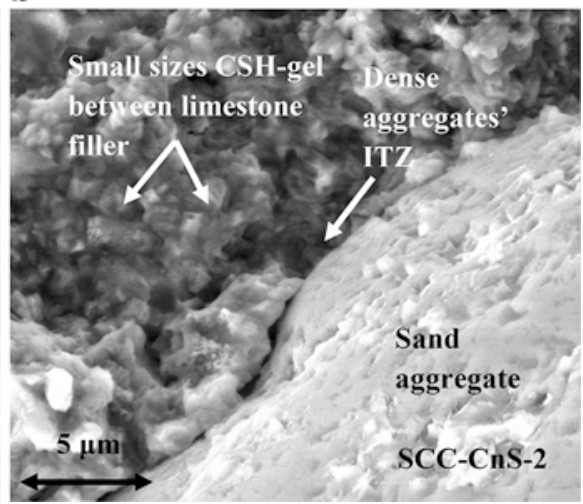

Fig. 7 Microstructure low vacuum (0.6 mbar) FEG-SEM photomicrographs of the SCC-CnS-2 mix, (a) cement matrix, (b) aggregate dense ITZ

by apparent compact and small-sized C-S-H gel and the absence of abundant gel porosity. As a consequence, a relatively denser ITZ was also confirmed by SEM (Fig. 7b). It is important to notice, that the needle-type structures or well grown Ca $(\mathrm{OH})_{2}$ crystals were not found in the microstructural analysis. The absence of needle-type hydrates in the cement matrix is unexpected. In general, as was explained for the reference SCC, ettringite is one of the hydrated phases formed in cement system with high amount of limestone additions. In the case of the SCC with CnS-2 the concentration of limestone was slightly decreased (from 179.4 to $151.8 \mathrm{~kg} / \mathrm{m}^{3}$ ), but this decrease should not influence the hydrates phases formation. Similarly, in system with amorphous nano-silica it was predicted (Lothenbach et al. 2011) that one of the stable phases formed is ettringite. Ettringite in longterm is only unstable when the $\mathrm{pH}$ of the pore solution falls below 10 due to further replacement of cement by silica. The dropping of the pore solution $\mathrm{pH}$ to values lower than 10 is predicted for amorphous silica additions higher than $35 \%$ by mass (Lothenbach et al. 2011). In the present research only $3.8 \%$ (based on the weight of cement) of nano-silica is added. One possibility that can explain the absence of ettringite is that the addition of nano-silica decreased the size of ettringite crystals, making much more difficult to identify by the used magnification of the ESEM. Also, smaller ettringite crystals are more susceptible to be discomposed by drying and vacuum conditions as was reported by (Taylor 1990). As was mentioned before, well grown $\mathrm{Ca}(\mathrm{OH})_{2}$ crystals were not found in the microstructural analysis. Changes in the amount and size of portlandite crystals are expected in the presence of amorphous silica as was established by different authors (Rols et al. 1999; Ji 2005; Sobolev and Ferrara 2005; Sobolev et al. 2006; Lin et al. 2008; Gaitero et al. 2008; Senff et al. 2009; Belkowitz and Armentrout 2010). The absence of well crystallized portlandite and the lower amounts of gel pores confirm that the addition of the nano-silica causes a refinement of the microstructure and probably induces the precipitation of small-sized CSH-gel that normally has a high stiffness and lower $\mathrm{Ca} / \mathrm{Si}$ ratio (Mondal et al. 2010). 


\section{Conclusions}

Based on the workability and durability properties obtained by the tests on a reference SCC and SCC mixes containing three types of nano-silica, the following conclusions can be drawn:

1. The results of the fresh state behavior of SCC demonstrated that concrete with an addition of $3.8 \%$ nano-silica (based on the mass of cement) shows similar flow properties and viscosity as the reference mix without nano-silica. Slightly increased air content in the mixes with nano-silica was measured due to a higher viscosity of the paste.

2. The water permeable porosity of the three SCC mixes was found to be similar. On the other hand, when nano-silica (CnS-2 and PnS-3 type) were added, the concrete becomes almost impermeable to the penetration of water under pressure. This can be explained by a refinement of the microstructure of the paste due to higher amount of pores with ink-bottle shape, as confirmed by MIP measurements.

3. The results of the fresh state behavior of SCC with olivine nano-silica (DOnS-8) demonstrated that concrete with addition of $3.8 \%$ based on the mass of cement shows better flowing and viscosity behavior than the reference mix. The high reactivity of the olivine nano-silica increased the water demand and resulted in higher air content of the mix. The compressive and tensile splitting strength of SCC with DOnS-8 was not improved due to the higher $w / c$ ratio. On the contrary, the water permeable porosity was similar to the reference mix. Nevertheless, when olivine nano-silica is added, the SCC mixes reduced their permeability to the penetration of water under pressure.

4. All durability indicators of the SCC studied (conductivity, chloride migration coefficients, and freeze-thaw resistance) were significantly improved with the addition of $3.8 \%$ of the three types of the nano-silica. Moreover, the SCC with colloidal nano-silica showed slightly better properties than the SCC with powder nano-silica.

5. The microstructural analysis of the hardened SCC reveals that, the addition of nano-silica resulted in a homogeneous microstructure, characterized by compact and small-sized CSH-gel. As a consequence, a denser ITZ was produced. The addition of nano-silica caused a refinement of the microstructure (less interconnected and finer pore structure) and induced the precipitation of small-sized CSH-gel, probably having a higher stiffness and lower $\mathrm{Ca} / \mathrm{Si}$ ratio.

6. The improvement of the microstructure resulted in a significant reduction of the permeability of concrete (good resistance against the penetration of chlorides and water under pressure) because of the microstructural densification and increased tortuosity of the pore system.

7. The high reactivity and faster pozzolanic behavior of the colloidal nano-silica (CnS-2) particles at early age produced a more refined microstructure than obtained for the SCC with powder nano-silica and olivine nano-silica. 
Nevertheless, the higher reactivity and agglomerated state appears to be the reason for the higher deviation standard obtained in the compressive strength results.

Acknowledgements This research was carried out under the project number M81.1.09338 in the framework of the Research Program of the Materials innovation institute (M2i) and The European Community's Seventh Framework Program, ProMine: Nano-particle products from new mineral resources in Europe, FP7-NMP-2008-LARGE-2 under grant agreement 228559. Furthermore, the authors thank ir. J.J.W. Gulikers for his help and assistance.

\section{References}

ASTM C1202 (2005) Standard test method for electrical indication of concrete's ability to resist chloride ion penetration. In: Annual book of ASTM standards, vol 04.02. American Society for Testing and Materials, Philadelphia, pp 1-6

Audenaert K, Boel V, De Schutter G (2007) Chloride migration in self compacting concrete. In: Proceedings of the fifth international conference on concrete under severe conditions: environment and loading (CONSEC'07), Tours, 4-6 June 2007, pp 191-298

Belkowitz JS, Armentrout D (2010) An investigation of nano-silica in the cement hydration process. In: Proceedings of the 2010 concrete sustainability conference, National Ready Mixed Concrete Association, Silver Spring, pp 1-15

BMC Certificatie BRL 1801 (2006) Nationale beoordelingsrichtlijn betonmortel. BMC Certificatie, Gouda (in Dutch)

Brunauer S, Emmet PH, Teller E (1938) Adsorption of gases in multimolecular layers. J Am Chem Soc 62:309-319

BS-EN 12390-8 (2009) Testing hardened concrete - depth of penetration of water under pressure. British Standards Institution-BSI and CEN European Committee for Standardization, pp 1-10

Byung WJ, Chang HK, Jae HL (2007) Investigations on the development of powder concrete with nano- $\mathrm{SiO}_{2}$ particles. KSCE J Civil Eng 11(1):37-42

CEN EN 197-1 (2000) Cement-part 1: composition and specifications and conformity criteria for common cements, European Commission for Standardization (CEN), pp 1-33

DIN ISO 9277 (2005) Determination of the specific surface area of solids by gas adsorption using the BET method. German Institute of Normalization-DIN, pp 1-19

EFNARC (2005) Specification and guidelines for self compacting concrete-SCC, Report, European Federation of Producers and Contractors of Specialist Products for Structures, Surrey, UK

Felekoglu B (2007) Utilization of high volumes of limestone quarry wastes in concrete industry (self-compacting concrete case). Resour Conserv Recycl 51:770-791

Gaitero JJ, Campillo I, Guerrero A (2008) Reduction of the calcium leaching rate of cement paste by addition of silica nanoparticles. Cem Concr Res 38:1112-1118

Garboczi EJ (1990) Permeability, diffusivity, and microstructural parameters: a critical review. Cem Concr Res 20:591-601

Hunger M (2010) An integral design concept for ecological self-compacting concrete. $\mathrm{PhD}$ thesis, Eindhoven University of Technology

Hüsken G, Brouwers HJH (2008) A new mix design concept for earth-moist concrete: a theoretical and experimental study. Cem Concr Res 38:1246-1259

Iler RK (1955) The colloid chemistry of silica and silicate. Cornell University Press, Ithaca, pp 1-250

Ji T (2005) Preliminary study on the water permeability and microstructure of concrete incorporating nano- $\mathrm{SiO}_{2}$. Cement Concr Res 35:1943-1947 
Khanzadi M, Tadayon M, Sepehri H, Sepehri M (2010) Influence of nano-silica particles on mechanical properties and permeability of concrete. In: Proceedings of the second international conference on sustainable construction materials and technologies, Universita Ploitecnica delle Marche, Ancona, 28-30 June 2010, pp 1-7

Kordts S, Breit W (2004-2006) Combined test method for assessing the workability of SCC-Flow cone, Concrete Technology reports, pp 7-15

$\mathrm{Li} \mathrm{G}$ (2004) Properties of high-volume fly ash concrete incorporating nano-SiO $\mathrm{S}_{2}$ Cem Concr Res 34:1043-1049

Lin KL, Chang WC, Lin DF, Luo HL, Tsai MC (2008) Effects of nano-SiO 2 and different ash particle sizes on sludge ash-cement mortar. J Environ Manage 88:708-714

Lothenbach B, Scrivener K, Hooton RD (2011) Supplementary cementitious materials. Cem Concr Res 41:1244-1256

Maghsoudi AA, Arabpour-Dahooei F (2007) Effect of nanoscale materials in engineering properties of performance self compacting concrete. In: Proceeding of the 7th international congress on civil engineering, Iran, pp 1-11

Mondal P, Shah SP, Marks LD, Gaitero JJ (2010) Comparative study of the effects of microsilica and nanosilica in concrete. In: Transportation research record: journal of the transportation research board, vol 2141. Transportation Research Board of the National Academies, Washington, DC, pp 6-9

NEN-EN 12390-9 (2006) Testing hardened concrete - freeze-thaw resistance - scaling. CEN European Committee for Standardization and Dutch Normalization-Institute, Delft (in English), pp 1-29

NEN-EN 206-1 (2008) Beton Deel 1: Specificatie, eigenschappen, vervaardiging en conformiteit. Nederlands Normalisatie Instituut, Delft, pp 1-72

Neville AM (2002) Properties of concrete, 4th edn. Prentice Hall/Pearson, Harlow, pp 537-576

Nili M, Ehsani A, Shabani K (2010) Influence of nano-SiO2 and micro-silica on concrete performance. In: Proceedings of the second international conference on sustainable construction materials and technologies, Universita Ploitecnica delle Marche, Ancona, Italy

Nordtest method NT Build 492 (1999) Concrete, mortar and cement-based repair materials: chloride migration coefficient from non-steady-state migration experiments. NT BUILD 492, Esbo, pp 1-8

Okamura H, Ozawa K (1995) Mix-design for self-compacting concrete. Concr Libr Jpn Soc Civil Eng JSCE 25:107-120

Plank J, Schroefl CH, Gruber M, Lesti M, Sieber R (2009) Effectiveness of polycarboxylate superplasticizer in ultra-high strength concrete: the importance of PCE compatibility with silica fume. J Adv Concr Technol 7(1):5-12, Japan

Quercia G, Brouwers HJH (2010) Application of nano-silica (nS) in concrete mixtures. In Fisher G, Geiker M, Hededal O, Ottosen L, Stang H (eds) The 8th fib international PhD symposium in civil engineering, Lyngby, 20-23 June, pp 431-436

Raiess-Ghasemi AM, Parhizkar T, Ramezanianpour AA (2010) Influence of colloidal nano-SiO2 addition as silica fume replacement material in properties of concrete. In: Proceedings of the second international conference on sustainable construction materials and technologies, Universita Ploitecnica delle Marche, Ancona, 28-30 June 2010, pp 1-8

Rols S, Ambroise J, Péra J (1999) Effects of different viscosity agents on the properties of selfleveling concrete. Cem Concr Res 29:261-266

Romero HL, Casati MJ, Galvez JC, Molero M, Segura I (2011) Study of the damage evolution of concrete under freeze-thaw cycles using traditional and non-traditional techniques. In: Proceeding of the XIII international conference on cement chemistry, Madrid, 4-8 July 2011, pp 1-7

Safiuddin M, Hearn N (2005) Comparison of ASTM saturation techniques for measuring the permeable porosity of concrete. Cem Concr Res 35:1008-1013

Sanchez F, Sobolev K (2010) Nanotechnology in concrete - a review. Constr Build Mater 24:2060-2071

Sari M, Prat E, Labastire JF (1999) High strength self-compacting concrete original solutions associating organic and inorganic admixtures. Cem Concr Res 29:813-818 
Scrivener KL, Kirkpatrick RJ (2008) Innovation in use and research on cementitious material. Cem Concr Res 38:128-136

Senff L, Labrincha JA, Ferreira VM, Hotza D, Repette WL (2009) Effect of nano-silica on rheology and fresh properties of cement pastes and mortars. Construct Build Mater 23:2487-2491

Sobolev K, Ferrara M (2005) How nanotechnology can change the concrete world - Part 1. Am Ceram Bull 84(10):14-17

Sobolev K, Flores I, Hermosillo R (2006) Nanomaterials and nanotechnology for highperformance cement composites. In: Proceedings of ACI session on nanotechnology of concrete: recent developments and future perspectives, Denver, 7 Nov 2006, pp 91-118

Spiesz P, Ballari MM, Brouwers HJH (2012) RCM: a new model accounting for the non-linear chloride binding isotherm and the non-equilibrium conditions between the free- and boundchloride concentrations. Construct Build Mater 27:293-304

Spiratos N, Page M, Mailvaganam NP, Malhotra VM, Jolicoeur C (2003) Superplasticizer for concrete fundamentals, technology, and practice. Supplementary Cementing Materials for Sustainable Development Inc., Ottawa, pp 1-321

Stark J, Wicht B (2001) Dauerhaftigkeit von Beton: Der Baustoff als Werkstoff, Birkhäuser, Basel (in German)

Taylor HFW (1990) Cement chemistry. Academic, London

Wei X, Zhang P (2011) Sensitivity analysis for durability of high performance concrete containing nanoparticles based on grey relational grade. Mod Appl Sci 5(4):68-73

Ye G (2003) Experimental study and numerical simulation of the development of the microstructure and permeability of cementitious materials. PhD thesis, Delft University of Technology, Delft, 18 Dec 2003, pp 1-189

Yogendran V, Langan BW (1987) Utilization of silica fume in high strength concrete. In: Proceedings of utilization of high strength concrete, Stavanger, Tapir Publisher, Trondheim

Zhang M, Ilsam J, Peethamparan S (2012) Use of nano-silica to increase early strength and reduce setting time of concretes with high volumes of slag. Cem Concr Compos 34:650-662 